\title{
Surgical strategy in transposition of the great arteries with aortic arch obstruction
}

\author{
Estratégia cirúrgica na transposição das grandes artérias associada à obstrução do arco aórtico
}

\author{
Bayard GONTIJO FILHO ${ }^{1}$, Fernando Antonio FANTINI², Roberto Max LOPES ${ }^{3}$, Cristiane Nunes MARTINS4, \\ Eliana Guimarães HEYDEN ${ }^{5}$, Erika Correa VRANDECIC ${ }^{6}$, Mario Osvaldo Vrandecic PEREDO²
}

RBCCV 44205-884

\begin{abstract}
Objective: Our results on the transposition of the great arteries with aortic arch obstruction were analyzed to establish our present protocol.

Method: From January 1998 to December 2005 we performed 223 arterial switch operations for transposition of the great arteries; $21(9.4 \%)$ patients had aortic arch obstruction associated. Aortic arch anatomy showed: localized aortic coarctation $(n=10)$ and coarctation with hypoplastic aorta $(n=6)$ and interrupted aortic arch $(n=5)$. Ventricular septal defect was present in $19(90.5 \%)$ patients. Size discrepancy between aorta and pulmonary artery and complex coronary artery anatomy were frequent findings. Surgical repair was performed in either one (14) or two stages (7). Aortic arch reconstruction was achieved either by resection and extended anastomosis (13) or by relocation of the ascending aorta (8).

Results: Hospital mortality was $23.8 \%(n=5)$; with one (11.1\%) death among the last nine patients. Reoperations
\end{abstract}

in the postoperative period including: bleeding (5), residual ventricular septal defect and unrecognized coarctation (1) or residual stenosis of the aortic arch (1). There were 2 late deaths caused by fungal infections and reoperation for severe aortic regurgitation. Three patients underwent procedures to relieve right ventricular outflow tract obstruction. Two patients have mild to moderate aortic regurgitation.

Conclusion: The surgical treatment of transposition of the great arteries with aortic arch obstruction is complex with high morbidity. Our present choice is single-stage treatment for all patients without using homologous or heterologous tissue for aortic arch reconstruction. We recommend resection and extended anastomosis for localized coarctation and relocation of the ascending aorta for hypoplastic or interrupted aortic arch.

Descriptors: Transposition of great vessels. Heart septal defects, ventricular. Cardiac Surgical Procedures/methods.

\footnotetext{
1. Adjunct Professor from UFMG Medical School; heart surgeon.

2. Cardiac surgeon.

3. Coordinator of the Department of Pediatric Cardiology; pediatric cardiologist.

4. Coordinator of the Department of Pediatric Cardiology; pediatric cardiologist.

5. Anesthesiologist.

6. Pediatric cardiologist.
}

Research performed at Biocor Institute, MG/Brazil.

Corresponding author

Bayard Gontijo Filho. Av. Alameda da Serra, 322, sala 304 - Nova Lima, MG. 
Resumo

Objetivo: Analisar nossa experiência no tratamento cirúrgico da transposição das grandes artérias (TGA) associada à obstrução do arco aórtico.

Método: Entre janeiro de 1998 e dezembro de 2005, realizamos 223 operações de Jatene para correção de TGA: $21(9,4 \%)$ pacientes apresentavam obstruções do arco aórtico. A anatomia do arco aórtico evidenciou: coarctação da aorta localizada ( $n=10)$; coarctação com hipoplasia tubular do arco aórtico (n=6); interrupção do arco aórtico $(n=5)$. Comunicação interventricular (CIV): 19 pacientes $(90,5 \%)$, sendo 11 do tipo Taussig-Bing. Desproporção importante entre aorta e artéria pulmonar e anomalias coronárias foram achados freqüentes. Houve 7 correções em dois estágios e 14 correções em um único estágio. A reconstrução do arco foi realizada por ressecção e anastomose término-terminal ampliada (13) ou por translocação da aorta ascendente (8).

Resultados: Houve cinco $(23,8 \%)$ óbitos hospitalares;

\section{INTRODUCTION}

Aortic arch obstruction (AAO) is a relatively frequent malformation in some forms of transposition of the great arteries (TGA) associated to ventricular septal defect (VSD) but it is rare in simple TGA with an intact interventricular septum. Apart from a highly unfavorable prognosis, this association makes the surgical approach complex requiring precise planning in order to obtain good results.

Initially, these patients were selected for two-stage surgical repair, with approach of the aortic arch in the first stage, usually accompanied with cerclage of the pulmonary artery (PA); in the second stage, repair of the TGA is performed. This form of treatment presented unfavorable results with a high morbimortality rate [1].

The introduction of single-stage repair of TGA plus AAO by Pigott in 1988 [2], along with improvements in neonatal surgical techniques, stimulated several centers to abandon the 2-stage repair and adopt the new methodology which is now generally used in the great majority of centers. Nevertheless, there are several characteristics of patients that directly interfere in the immediate and long-term postoperative outcomes. The anatomical nature of AAO, a higher incidence of coronary anomalies, differences in the calibers of the aorta and the PA, the occurrence of subaortic stenosis and a higher incidence of aortic regurgitation over the long term are among the factors that directly affect the definition of the operative technique to be used, making this group of patients a challenge for the surgical team. apenas um $(11,1 \%)$ nos últimos nove casos consecutivos. Reoperações no período hospitalar: revisão de hemostasia (5), CIV residual + coarctação não identificada (1), estenose residual de arco aórtico (1). Após a alta, houve dois óbitos e três pacientes foram submetidos a reintervenções para estenose da via de saída do ventrículo direito.

Conclusão: $O$ tratamento da transposição das grandes artérias associada à obstrução do arco aórtico apresenta alta complexidade e morbi-mortalidade. Empregamos as correções em um e em dois estágios, obtendo resultados comparáveis. Nossa preferência atual é pela correção precoce em um único estágio para todos os pacientes, independente de sua configuração anatômica.

Descritores: Transposição dos grandes vasos. Defeitos do septo interventricular. Procedimentos cirúrgicos cardíacos, métodos.

Based on our current conduct, in this research we tried to analyze our experience in patients with TGA plus AAO who underwent either the 2-stage repair or simultaneous repair.

\section{METHOD}

Two hundred and twenty-three Jatene operations to treat TGA were performed from January 1998 to December 2005 at the Biocor Institute. Twenty-one patients (9.4\%) had concomitant AAO. The pre-operative diagnosis was performed basically by echocardiography, with cardiac catheterism being used as an alternative in cases that were hard to define or when a better anatomical definition was necessary to choose the surgical procedure. The majority of cases occurred in TGA children with VSD or with complex Taussig-Bing, which is rare in cases of patients with simple TGA(Table 1).

Table 1. Transposition of the great arteries with aortic arch obstruction. Frequency vs. diagnosis

\begin{tabular}{lcccc}
\hline Diagnosis & $\begin{array}{c}\text { Number of } \\
\text { patients }\end{array}$ & TGA+AAO & $\%$ & p-value \\
\hline Simple TGA & 138 & 2 & 1.5 & 0.008 \\
TGA + VSD & 68 & 8 & 11.8 & 0,77 \\
Taussig-Bing & 17 & 11 & 64.7 & $<0.001$ \\
Total & 223 & 21 & 9.4 & \\
\hline
\end{tabular}

TGA - Transposition of the great arteries. AAO - Aortic Arch obstruction. VSD - Ventricular septal defect 
The low incidence of AAO in simple TGA and the high incidence with Taussig-Bing presented a statistical significance. The ages of the patients ranged from 6 to 88 days (mean $=27.5$ ) with a predominance of male infants (75\%). The body weights ranged from 2.4 to $4.6 \mathrm{~kg}$ (mean = $3.4 \mathrm{~kg})$.

In relation to the type of aortic arch obstructive lesion, we identified 10 cases of localized aortic coarctation, six cases of coarctation associated with tubular hypoplasia of the aortic arch and five cases of aortic arch interruption (Figure 1). To define tubular hypoplasia of the aortic arch which requires surgery, we used the criterion adopted by Karl et al. [3], who considered the diameter of the aortic arch in relation to the patient's body weight. The coronary anatomy of the 21 patients was identified according to the classification by Yacoub et al. [4]. The incidence of classic coronary distribution (Type IA) was 57.1\%. This incidence was significantly lower to that found in the rest of the group of patients $(\mathrm{n}=202)$ who underwent the Jatene surgery $(76.7 \%)-p=0.43$. Another common anatomical finding among the patients was the accentuated difference between the calibers of the PA and Aorta in $76.2 \%$ of the cases.

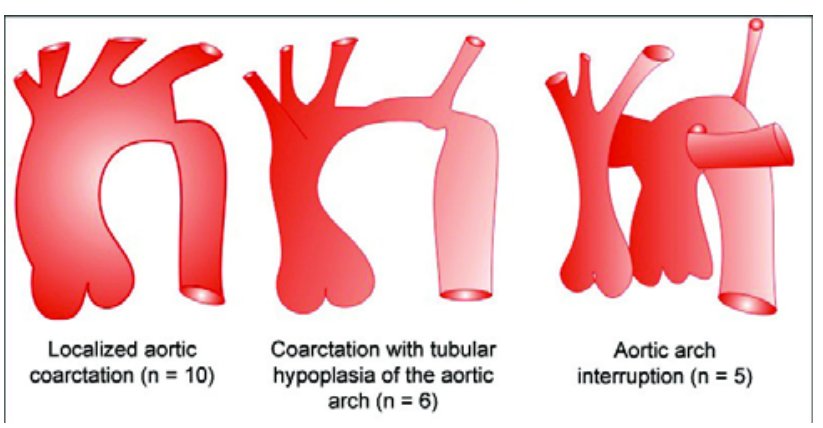

Fig.1 - TGA + obstruction of the aortic arch - anatomy of the aortic arch

\section{Operative technique}

Two strategies were applied to correct transposition associated with AAO; 2-stage and single-stage repair. The choice for the surgical procedure was according to the period of the study and was essentially based on the experience acquired when managing the children and their anatomical characteristics. Two-stage repair was more common in the first years in children with localized coarctation. Single-stage arterial switch was mainly indicated in patients with hypoplastic or interrupted aortic arch which was the most commonly used technique over the last few years.

Figure 2 shows the frequency of utilizing both techniques during our experience. Demographic data of the 21 patients were divided according to the operative procedure for comparison (Table 2). $\square$ Correção em 2 tempos ( $n=7)$ घCorreção simultânea $(n=14)$

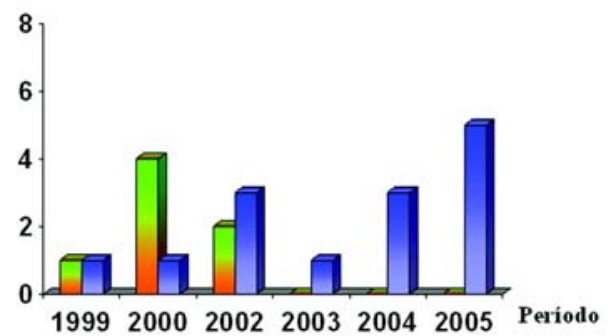

Fig 2. - TGA + obstruction of the aortic arch - surgical strategy versus correction time

Table 2. Transposition of the great arteries with aortic arch obstruction. Demographic data vs. Surgical strategy

\begin{tabular}{|c|c|c|c|}
\hline & & $\begin{array}{c}\text { Two-stage } \\
\text { repair } \\
(n=7)\end{array}$ & $\begin{array}{c}\text { Single-stage } \\
\text { repair } \\
(\mathrm{n}=14)\end{array}$ \\
\hline \multicolumn{2}{|c|}{ Male } & $71.4 \%$ & $78.6 \%$ \\
\hline \multicolumn{2}{|c|}{ Weight (m) } & $3.38 \pm 0.31 \mathrm{~kg}$ & $3.41 \pm 0.26$ \\
\hline \multicolumn{2}{|c|}{ Age (m) } & $46.0 \pm 6.3$ days & 18. $2 \pm 2.1$ days \\
\hline Frequency & Simple TGA & 0 & 2 \\
\hline vs & TGA + VSD & 4 & 4 \\
\hline diagnosis & T. Bing & 3 & 6 \\
\hline
\end{tabular}

TGA - Transposition of the great arteries. VSD - Ventricular septal defect. T. Bing - Taussig-Bing

\section{Two-stage repair}

The 2-stage repair technique was performed in seven patients. For six children, repair was performed electively, with coarctation being corrected through left thoracotomy in the first stage. The technique employed involved resection of the coarcted area and end-to-end anastomosis extended to the base of the aortic arch. Only one of these children presented aortic arch hypoplasia but extension was possible because of the extensive mobilization of the descending aorta and of the aortic arch. Cerclage of the PA was not associated in any of the patients.

The second stage of the anatomical repair of TGA occurred after an interval ranging from 3 to 10 days (mean $=6.7$ days), without releasing the patient from hospital. The technique for anatomical repair of TGA followed the principles employed by our group and described elsewhere [5]. In one patient, repair of coarctation was performed after Jatene surgery, as diagnosis was not made in the pre- 
operative evaluation. This case did not follow the same parameters of the classic 2-stage repair, but it is worthy of mention to highlight the difficulties found in the preoperative diagnosis of some patients.

\section{Single-stage repair}

This was the technique that prevailed in the latter years of our experience. Preparation for simultaneous repair of TGA plus AAO was the same as that performed for the normal Jatene surgery with the addition of a second perfusion cannula in the arterial channel in patients with aortic arch interruption. We induced deep hypothermia $\left(18^{\circ} \mathrm{C}\right)$ with a short period of total circulatory arrest (mean time $=16.5$ minutes) for the initial approach of the aortic arch. Two techniques were employed for aortic arch reconstruction. Resection with end-to-end anastomosis extended to the base of the aortic arch was employed in six patients and translocation of the ascending aorta, as described by Liddicoat et al. [6] in 8 patients (Figure 3).

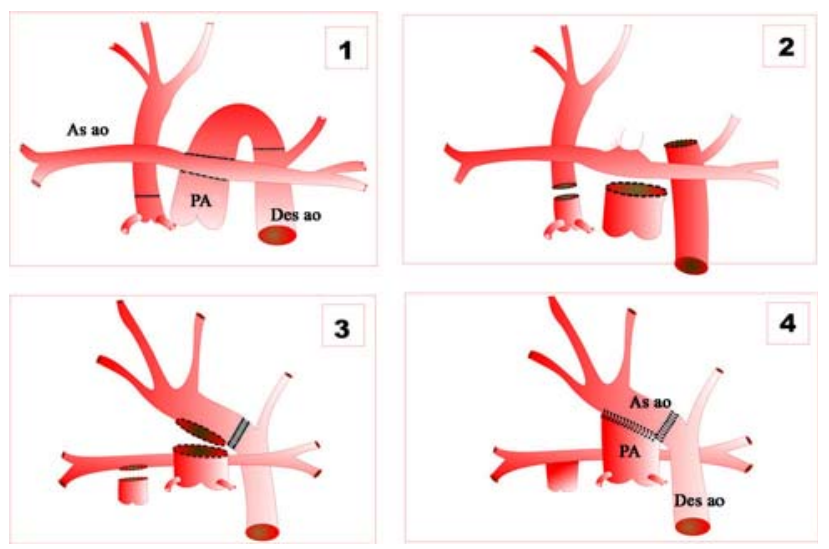

Fig 3 - TGA + obstruction of the aortic arch - translocation of the ascending aorta

Resection with end-to-end anastomosis was performed basically in cases of localized aortic coarctation with good development of the aortic arch. Only one child had tubular hypoplasia of the aortic arch underestimated which resulted in significant residual stenosis and immediate postoperative repair was required using a reverse patch of the left subclavian artery. The translocation of the ascending aorta technique was initially performed in patients with TGA with aortic arch interruption. Afterwards, we extended its use to patients with significant aortic arch hypoplasia.

For aortic translocation, we sectioned the ascending aorta immediately above the aortic valve commissures. After ample mobilization of the cervical branches, we performed end-to-end anastomosis, between the distal stump of the ascending Aorta and the descending Aorta, after resection of the coarcted area. Reconstruction of the left ventricle outflow tract was completed with anastomosis of the PA to the ventral face of the ascending aorta. In all cases, we used the Lecompte maneuver. On concluding the surgical procedure with the completion of aortic arch reconstruction the arterial flow was reestablished and the patient warmed to $28^{\circ} \mathrm{C}$.

Accentuated differences between the calibers of the Aorta and PA were treated in two ways. Initially, we extended the ascending aorta with a tiny autologous pericardium patch, adapting it to the larger caliber of the PA or increasing the incision in the ventral face of the Aorta in cases of translocation. More recently, we reduced the PA with resection of the arterial wall segment of the posterior Valsalva's sinus. Thus, the neoaortic root is remodeled diminishing its caliber and the sino-tubular region in order to reduce the incidence of aortic insufficiency. A second sternotomy was employed in 13 (61.9\%) of the 21cases, which is significantly higher than what is found in series using Jatene's surgery ( $p<0.01)$. It is necessary to mention that no homologous, heterologous or prosthetic tissues were used to reconstruct the aortic arch in the 21 patients.

The Student t-test was applied to comparatively evaluate the groups in respect to qualitative data. The data are expressed as medians or means \pm standard deviation. The level of significance for the analysis was set at $5 \%$.

\section{RESULTS}

\section{Hospital mortality}

Two-stage repair

There were only two deaths $(28.6 \%)$ in the immediate postoperative period. The first death occurred in a patient in whom aortic coarctation was discovered in the postoperative period of anatomical correction of TGA. The infant had evolved with refractory cardiac insufficiency as well as residual VSD when the coarctation was discovered; a reoperation was performed on the $6^{\text {th }}$ postoperative day (POD) to correct both problems. In the postoperative period, the patient presented with low cardiac output syndrome, total AV block and renal insufficiency and died on the following day. The second death occurred in a child with type IIID coronary anatomy (Yacoub) [4] in whom we had per-operative difficulties with the reimplantation of the coronary artery, requiring review of an anastomosis. The patient's sternum had been open for 3 days when adequate conditions to close it arose. On the $8^{\text {th }}$ POD, the patient presented with a sudden electrocardiographic alteration leading to cardiac arrest in asystole without recovery. The other five children had relatively uneventful postoperative periods. 


\section{Single-stage repair}

There were three deaths (21.4\%) in this group. The first death was due to obstruction of the endotracheal tube on the $3^{\text {rd }}$ POD. The second death occurred in a child that presented with a pulmonary hypertension crisis and increased bleeding in the immediate postoperative period leading to significant hemodynamic repercussions. The sternum was left open until the $6^{\text {th }}$ POD. The patient recovered well until the $10^{\text {th }} \mathrm{POD}$, when hypertensive pneumothorax with hypoxemia and cardiac arrest refractory to resuscitation maneuvers occurred. The third death occurred in a child who was submitted to translocation of the ascending Aorta. The infant presented with severe bleeding in the $5^{\text {th }}$ postoperative hour, originating from the distal angle of the anastomosis of the PA with the Aorta.

Among the survivors, three children were also submitted to review of hemostasis in the ICU. One child, who has already been mentioned, submitted to resection with end-to-end anastomosis, presented with low cardiac output, oliguria and residual stenosis of the aortic arch. The infant was reoperated on the $2^{\text {nd }} \mathrm{POD}$, with enlargement of the aortic arch using a patch of the left subclavian artery (reverse Walhausen), with optimum recovery. In the last nine patients, who were all submitted to simultaneous repair, there was an improvement in the surgical outcomes with only one death (11.1\%). Table 2 shows the main variables observed in patients who died in the immediate postoperative period.

\section{Late evolution}

There were two deaths after discharge. Both patients had been submitted to simultaneous repair. The first death was of a TGA child with aortic arch interruption, who presented progressive aortic insufficiency from the $5^{\text {th }}$ postoperative month, with significant cardiac insufficiency. The patient was reoperated on in the $6^{\text {th }}$ postoperative month, with valvuloplasty of the systemic valve. However, moderate valve insufficiency remained which led to significant ventricular dysfunction and death on the $1^{\text {st }}$ POD.

The second death was of a child with aortic arch interruption, whose postoperative recovery was complicated by sepsis after a long period in the ICU. After discharge, the patient presented pulmonary re-infection by fungi and died in the $2^{\text {nd }}$ postoperative month. Three Taussing-Bing children were submitted to reviews of the right ventricle outflow tract, all after more than three years of evolution. The first patient was reoperated with the placement of a conduct between the right ventricle (RV) and pulmonary trunk (PT) because the right coronary artery crossed the RV outflow tract. The other two children were submitted to balloon dilatation with good immediate results.
Of a total of 21 patients, 14 continue having outpatient follow ups, five after translocation of the ascending aorta and nine after resection and end-to-end anastomoses. Dilatation of the neoaortic root is a relatively frequent finding among these patients, however only two patients evolved with slight to moderate aortic insufficiency and the rest with slight or no regurgitation. All patients presented a good clinical evolution, without neurological disorders and without evidence of significant aortic restenosis.

\section{DISCUSSION}

The presence of AAO is rare in patients presenting with TGA with intact interventricular septa, but it is more common in TGA with VSD and very common in TaussigBing cases. The frequency of patients with TGA of 8-10\%, demonstrates the importance of this association [2]. Despite the advances in surgical techniques and in postoperative intensive care, the treatment of the association of TGA with AAO is highly complex. The definition of the best operative strategy (single or two-stage), as well as the presence of anatomical variations related to the aortic arch anatomy, the coronary distribution, to the position and differences in the caliber of the great vessels and the RV outflow tract, are important factors when choosing the best procedure and in determining the immediate and long term outcomes.

\section{Two-stage repair versus single-stage repair}

The patients with TGA plus AAO were initially selected for 2-stage repair, which was the customary technique until the beginning of the last decade. In the first stage of this procedure, the AAO is approached by left thoracotomy and, as a rule, associated to cerclage of the PA. The intracardiac repair occurs usually after some months. Hospital mortality was high with this approach, ranging from 31 to $64 \%$ [7,8]. The main factors for this high mortality rate were the presence of tubular hypoplasia of the aortic arch in many patients, the deleterious effects of PA cerclage and the morbimortality accumulated using both procedures.

Single-stage arterial switch was introduced by Pigot el al. [1], when they utilized this technique in five patients. Planche et al. [7] confirmed the better results obtained with simultaneous repair in 1993 by comparing their experience using both techniques. Since then, there has been a growing trend to adopt simultaneous repair as the main choice in patients with TGA and AAO $[9,10]$.

We performed both treatment strategies in our study. The 2-stage repair was the most common technique in the first years, as we believed it to be less complex and safer than simultaneous repair. Different to previous reports, our 2 -stage repair cases were programmed to be carried out 
during a single hospitalization period, with a short interval between the procedures. This is also the reason that we did not associate PA cerclage in any of the cases. The mean interval between the two stages was 6.7 days.

We obtained good results with this strategy and no deaths occurred in the five initial patients. The sixth patient, who underwent an elective operation, died after the anatomical repair, due to a technical problem with coronary re-implantation. The other patient who died was not characteristic of the classic 2-stage repair as the approach to AAO occurred after anatomical repair as coarctation was not recognized in the preoperative evaluation.

The hospital mortality (16.6\%) of the six electively operated patients and the absence of late complications observed in our study using the 2-stage repair demonstrate that it is a valid alternative for patients with TGA plus AAO. With the diagnosis of cases with a more complex anatomy of the aortic arch, which are not eligible for the 2-stage procedure, we started to employ simultaneous repair, the most frequently used technique over the last few years. With the acquired experience, simultaneous repair started to be used in all patients with TGA plus AAO. Fourteen patients were operated on using this strategy with three deaths but with only one directly related to the technique. Over the last two years, nine patients were consecutively operated on employing simultaneous repair with only one death being reported, reducing the mortality rate to $11.1 \%$.

Our current choice to treat TGA with AAO is simultaneous repair because of the better results achieved using the technique and the experience that was accumulated over the years. We believe that 2-stage repair can be a valid alternative, particularly for patients with localized aortic coarctation, as tubular hypoplasia of the aortic arch when operated by thoracotomy, leads to increased rates of aortic restenosis [2,7]. In patients with localized coarctation, we obtained good results with the 2stage option, shortening the interval between the stages and avoiding cerclage of the PA. Two-stage repair can be a valid alternative in patients with neurological lesions or in those with active infections, delaying the second stage until there is an improvement in the patient's clinical conditions [8].

\section{Aortic arch reconstruction}

There are several techniques of aortic arch reconstruction with the choice of method mainly depending on the anatomy of the obstruction. Aortic coarctation with good development of the aortic arch can be satisfactorily treated with classic resection and extended anastomosis [7]. This technique can be achieved using left thoracotomy in the first stage or by sternotomy in simultaneous repair cases. As previously mentioned, tubular hypoplasia of the aortic arch is an important anatomical factor which is not favorable to the classic resection technique.

The definition by which tubular hypoplasia of the aortic arch must be surgically treated is controversial. We know that reestablishing the anterograde flow through the ascending Aorta in patients with preferential circulation through the arterial channel enables normal development of the arch in many patients with hypoplasia of the aortic arch. In some patients, the hypoplasia may not regress but may persist as an obstructive factor in the postoperative period.

Hence, the preoperative assessment is really important and will directly influence the decision of which procedure should be utilized. We used the proposal of Karl et al. [3], which compares the aortic arch caliber to the infant's body weight. If the diameter of the transverse arch at echocardiography is smaller than the body weight plus 1 , the choice should be surgical. For example, the aortic arch is considered hypoplastic if the aortic arch is less than 4 $\mathrm{mm}(3+1)$ in a $3-\mathrm{kg}$ child. Even so, a reoperation was necessary in the immediate postoperative period of one of our patients to correct significant residual stenosis of the aortic arch due to incorrect assessment of the hypoplasia. This fact demonstrates the difficulties encountered in the preoperative evaluation.

Once the surgical approach for tubular hypoplasia is defined, we use translocation of the ascending aorta as described by Liddicoat et al. [6] in 1994, to correct it. The authors used it in cases of TGA associated with aortic arch interruption. Other authors recommend enlarging the aortic arch and ascending Aorta using a homograft [10] or autologous pericardium [11] to correct tubular hypoplasia. The translocation technique, apart from its application for both tubular hypoplasia of the aortic arch and aortic arch interruptions, is performed without using autologous or homologous patches that may calcify, causing complications in the future. Today the selection of the technique for aortic arch reconstruction is well established in our group and is defined by the aortic arch anatomy. In cases of localized coarctation, we recommend resection with extended anastomosis and, in patients with hypoplasia or interruption of the aortic arch we use translocation of the ascending aorta. With this approach, there is no record of re-coarctation in any of our surviving patients.

\section{Late residual lesions}

Patients with TGA and with AAO that survived surgical correction present with a higher rate of re-interventions and late residual lesions than patients submitted to correction of TGA without alterations of the aortic arch. The main residual lesion is stenosis of the RV outflow tract due to its anatomy and not due to the surgical approach. 
Anterior deviation to the right of the interventricular septum in patients with Taussig-Bing and in some cases of TGA plus VSD may result in RV hypoplasia involving the subaortic region. Furthermore, septo-parietal hypertrophic trabeculations and abnormal insertions of atrioventricular valves can contribute to the existence of sub-pulmonary gradients [12]. We identified three cases of significant restenosis of the RV outflow tract in our surviving patients $(\mathrm{n}=14)$.

A child was reoperated, due to the tubular nature of the obstruction, with the placement of a RV-PT conduct because the large right coronary artery crossed the outflow tract. Two other patients were submitted to balloon valvuloplasty providing hemodynamic improvement. They are still being accompanied due to the possibility of relapse. The other common finding in the late evolution of these patients is dilatation of the neoaortic root and a higher incidence of aortic regurgitation [13]. Aortic regurgitation, although slight in most patients, is a concern because of its progressive nature. Several factors have been associated to the appearance of aortic regurgitation after the anatomical repair of TGA, including the techniques for coronary reimplantation [14] and closure of the VSD [13].

We believe that great dilatation of the pulmonary trunk continuously submitted to systemic pressure after repair leads to a progressive separation of the sino-tubular region, with consequent valvar regurgitation. Postoperative echocardiographic and angiographic evaluations show significant dilatation of the neoaortic root in most of these patients. One of our patients with TGA plus aortic arch interruption evolved in a short period of time to severe aortic insufficiency, which required re-intervention in the $6^{\text {th }}$ month of the postoperative period.

Approximately one year ago, we started reducing the PA caliber in children with significant differences between the aorta and PA, with the resection of a fragment of the arterial wall close to the posterior commissure. Thus, we achieved better remodeling of the aortic root and we believe this is going to help to preventive the development of valvar regurgitation. The follow-up of these patients thus far presents good echocardiographic evolution, with a more uniform sino-tubular region and good coaptation of valvar leaflets. Longer follow-up periods are necessary to evaluate this group of patients to define the real validity of the procedure.

\section{Limitations of the study}

We studied 21 consecutive patients with complex and uncommon heart disease. This represents a relatively small population over a short postoperative follow-up for statistical analysis. Furthermore, this study did not follow a linear protocol as there were two treatment strategies being applied without rigid selection criteria. Hence, the surgeries are complex and the comparison of the results observed with experience may not be precise. Despite adopting simultaneous repair as our current conduct, we believe that the 2-stage repair may be a valid option for some patients and for hospitals with less experience in the correction of complex heart diseases in the neonatal period.

The surgical treatment of TGA associated to AAO is complex and presents several variables that are involved in the final outcome. Our current option is simultaneous repair without homologous or heterologous tissues for the reconstruction of the aortic arch, with resection and end-to-end anastomosis being indicated in patients with localized aortic coarctation and translocation of ascending aorta in patients with hypoplasia or interruption of the aortic arch.

\section{REFERENCES}

1. Pigott JD, Chin AJ, Weinberg PM, Wagner HR, Norwood WI. Transposition of the great arteries with aortic arch obstruction. Anatomical review and report of surgical management. J Thorac Cardiovasc Surg. 1987;94(1):82-6.

2. Tchervenkov CI, Korkola SJ. Transposition complexes with systemic obstruction. Pediatric Cardiac Surgery Annual of the Seminars in Thoracic and Cardiovascular Surgery;2001;4:71-82.

3. Karl TR, Sano S, Brawn W, Mee RB. Repair of hypoplastic or interrupted aortic arch via sternotomy. J Thorac Cardiovasc Surg. 1992;104(3):688-95.

4. Yacoub MH, Radley-Smith R, MacLaurin R. Two-stage operation for anatomical correction of transposition of the great arteries with intact interventricular septum. Lancet. 1977;1(8025):1275-8. 
5. Gontijo Filho B, Fantini FA, Lora HM, Martins C, Lopes RM, Hayden E, et al. Reconstrução da artéria pulmonar na operação de Jatene. Rev Bras Cir Cardiovasc. 2001;16(3):236-43.

6. Liddicoat JR, Reddy VM, Hanley FL. New approach to greatvessel reconstruction in transposition complexes with interrupted aortic arch. Ann Thorac Surg. 1994;58(4):1146-50.

7. Planche C, Serraf A, Comas JV, Lacour-Gayet F, Bruniaux J, Touchot A. Anatomic repair of transposition of the great arteries with ventricular septal defect and aortic arch obstruction. Onestage versus two-stage procedure. J Thorac Cardiovasc Surg. 1993;105(5):925-33.

8. Vouhe PR, Trinquet F, Lecompte Y, Vernant F, Roux PM, Touati G, et al. Aortic coarctation with hypoplastic aortic arch. J Thorac Cardiovasc Surg. 1988;96(4):557-63.

9. Comas JV, Mignosa C, Cochrane AD, Wilkinson JL, Karl TR. Taussig-Bing anomaly and arterial switch: aortic arch obstruction does not influence outcome. Eur J Cardiothorac Surg. 1996:10(12):1114-9.

10. Tchervenkov CI, Tahta SA, Cecere R, Beland MJ. Single-stage arterial switch with aortic arch enlargement for transposition complexes with aortic arch obstruction. Ann Thorac Surg. 1997;64(6):1176-81.

11. Pocar M, Villa E, Degandt A, Mauriat P, Pouard P, Vouhe PR. Long-term results after primary one-stage repair of transposition of the great arteries and aortic arch obstruction. J Am Coll Cardiol. 2005;46(7): 1331-8.

12. Milanesi O, Ho SY, Thiene G, Frescura C, Anderson RH. The ventricular septal defect in complete transposition of the great arteries: pathologic anatomy in 57 cases with emphasis on subaortic, subpulmonary and aortic arch obstruction. Hum Pathol. 1987;18(4):392-6.

13. Mohammadi S, Serraf A, Belli E, Aupecle B, Capderou A, Lacour-Gayet F, et al. Left-sided lesions after anatomic repair of transposition of the great arteries, ventricular septal defect, and coarctation: surgical factors. J Thorac Cardiovasc Surg. 2004;128(1):44-52.

14. Formigari R, Toscano A, Giardini A, Gargiulo G, Di Donato R, Picchio FM, et al. Prevalence and predictors of neoaortic regurgitation after arterial switch operation for transposition of the great arteries. J Thorac Cardiovasc Surg. 2003;126(6):1753-9. 